\title{
The relative roles of advanced glycation, oxidation and aldose reductase inhibition in the development of experimental diabetic nephropathy in the Sprague-Dawley rat
}

\author{
T. Soulis-Liparota, M. E. Cooper, M.Dunlop, G. Jerums \\ Department of Medicine, University of Melbourne, Heidelberg Repatriation, Austin and Royal Melbourne Hospitals, Melbourne, \\ Victoria, Australia
}

\begin{abstract}
Summary Advanced glycation is an important pathogenic mechanism in the development of diabetic complications. However, other biochemical processes, such as the polyol pathway or lipid and protein oxidation which can interact with advanced glycation can also yield tissue fluorescence and may also be implicated in the genesis of diabetic microangiopathy. Aminoguanidine is an inhibitor of advanced glycation, but it is not known if all of its effects are mediated by this mechanism. The present study explores the relative contributions of aldose reductase, oxidative stress and advanced glycation on the development of aortic and renal fluorescence and urinary albumin excretion in streptozotocin diabetic rats. The study groups included non-diabetic (control), streptozotocin diabetic rats and diabetic rats receiving aminoguanidine, the anti-oxidants butylated hydroxytoluene and probucol and the aldose reductase inhibitor, ponalrestat. Serial measurements of glycaemic control and urinary albumin excretion were performed every 8 weeks. At 32 weeks, animals were killed, tissues removed and collagen extracted for measurement of fluorescence. Diabetic rats had increased fluorescence in aorta, glomeruli and renal tubules. Aminoguanidine prevented an increase in fluorescence at all three sites suggesting that diabetes-related tissue fluorescence is predomi-
\end{abstract}

nantly due to advanced glycation. Ponalrestat retarded fluorescence in aorta only and butylated hydroxytoluene attenuated fluorescence at the renal sites but not in the aorta. Diabetic rats had increased renal cortical sorbitol levels. Ponalrestat normalized renal cortical sorbitol levels but aminoguanidine did not affect this parameter. The only agent to decrease plasma thiobarbituric acid reactive substances was butylated hydroxytoluene. Diabetic rats developed albuminuria over the 32-week period. This increase in urinary albumin excretion was only attenuated significantly by aminoguanidine therapy, but not by probucol or ponalrestat. The effects of butylated hydroxytoluene on albuminuria were intermediate between aminoguanidine-treated and untreated diabetic rats. The failure of either antioxidants or aldose reductase inhibition to reproduce the renal effects of aminoguanidine suggest that aminoguanidine may act predominantly via inhibition of advanced glycation and not via the alternative biochemical processes evaluated in this study. [Diabetologia (1995) 38: 387-394]

Key words Advanced glycation, oxidation, aldose reductase inhibition, diabetic nephropathy, aminoguanidine, ponalrestat, probucol, butylated hydroxytoluene.
Received: 14 April 1994 and in revised form: 4 October 1994

Corresponding author: Dr. T.Soulis-Liparota, Department of Medicine, Heidelberg Repatriation Hospital, West Heidelberg, Victoria 3081, Australia

Abbreviations: AGE, Advanced glycated end products; $\mathrm{AG}$, aminoguanidine, TBARS, Thiobarbituric acid reactive substances; BHT, butylated hydroxytoluene.
The development of diabetic nephropathy may be related not only to formation and subsequent accumulation of advanced glycation end products (AGEs), but also to other biochemical processes including oxidation [1] and activation of the polyol pathway [2]. AGEs are derived from the non-enzymatic glycation of proteins such as collagen with subsequent further rearrangement to yield glucose-derived cross-links, 
and fluoresce at specific wave lengths. However, the observed fluorescence in diabetic tissues could result from other processes that are increased in diabetes mellitus such as fructosylation. Fructosylation occurs after glucose is converted by aldose reductase to sorbitol and then to fructose. The reaction of fructose with protein yields fluorescent products at a rate ten times faster than glucose [3] and may be more potent in damaging proteins [4]. Oxidation has been shown to produce fluorescent products and to interact with the advanced glycation process [5]. Phospholipids, for example, react directly with glucose to form AGEs which subsequently initiate lipid oxidation. Phospholipid-linked AGEs are able to mimic the absorbance and fluorescence of AGEs [1]. Hyperglycaemia itself may contribute to oxidative events by forming glycation products that can propagate free radical events [6].

Aminoguanidine, a phenylhydrazine compound, has been previously shown by our group [7] to reduce collagen-related fluorescence in the aorta as well as the kidney (renal tubules and glomeruli) after 32 weeks of streptozotocin diabetes. Aminoguanidine also attenuated the rate of development of albuminuria and prevented mesangial expansion in diabetic rats. The present study explores the relative contributions of advanced glycation, oxidative stress and the polyol pathway in the pathogenesis of experimental diabetic nephropathy. Since the exact nature of AGEs is poorly characterised and the links between advanced glycation and other biochemical processes have been poorly elucidated, specific inhibitors of the putative biochemical processes were used in a rat model of experimental diabetes over a 32week study period. Major endpoints included albuminuria and markers of the individual biochemical processes studied.

\section{Materials and methods}

Male Sprague-Dawley rats, 6 weeks of age, weighing between 200 and $250 \mathrm{~g}$ were randomized into control or diabetic rats. Diabetes was induced by intravenous injection of streptozotocin (60 $\mathrm{mg} / \mathrm{kg}$ body weight in citrate buffer, $\mathrm{pH} 4.5)$ after an overnight fast and all animals with plasma glucose levels greater than $20 \mathrm{mmol} / 1$ after 1 week were included in the study. The control group was sham injected with citrate buffer alone. Diabetic animals were further randomized to five groups which received no therapy, aminoguanidine hydrogen carbonate (Fluka Chemica, Buchs, Switzerland) $1 \mathrm{~g} / \mathrm{l}$ in drinking water, the antioxidant, Probucol (Marion Merrell Dow, Cincinnatti, Ohio, USA) $1 \%$ in the diet [8], the anti-oxidant Butylated hydroxytoluene (BHT) (Aldrich, Castle Hill, Australia) $0.4 \%$ in the diet $[9,10]$ or the aldose reductase inhibitor Ponalrestat (ICI, Macclesfield, UK) $0.03 \%$ in the diet [11]. Two lipid-soluble antioxidants were used; $\mathrm{BHT}$ and probucol, the latter possessing cholesterol-lowering as well as antioxidant properties [10]. All rats were given free access to food throughout the study (GR2 rat cubes, Clark King and Co, Melbourne, Australia). Probucol, BHT and ponalrestat were coated onto the pellets.
Diabetic rats received $2 \mathrm{IU}$ ultralente insulin (Ultratard HM, Novo Industries, Bagsvaerd, Denmark) every second day to maintain body weight and improve survival over the 32-week period of the study. Rats were caged in groups of three. At eight weekly intervals, rats were weighed and placed in metabolic cages (Iffa Credo, L'Abresele, France) for collection of 24-h urine samples used for measurement of albuminuria. Blood was collected from the tail vein for measurement of plasma glucose and glycated haemoglobin at 8-week intervals.

Plasma glucose was measured by a glucose oxidase technique [12] and glycated haemoglobin was measured by a highperformance liquid chromatography technique [Bio-Rad, Richmond, Calif., USA) [7]. Urine from diabetic rats was tested on a regular basis for the presence of ketones (Ketostix, Miles, Mulgrave, Australia) but ketonuria was not detected in any diabetic animal throughout the study. Urinary albumin concentration was measured by radioimmunoassay [13]. The interassay coefficient of variation was $7 \%(n=50)$ at a concentration of $180 \mathrm{ng} / \mathrm{ml}$ and the detection limit of the assay was $31.2 \mathrm{ng} / \mathrm{ml}$.

At 32 weeks rats were anaesthetised with pentobarbital sodium (Nembutal, Bomac, Asquith, Australia) and the left kidney was excised followed by the removal of the lower abdominal aorta and right and left common iliac arteries. These tissues were immediately snap frozen in liquid $\mathrm{N}_{2}$ and stored at $-80^{\circ} \mathrm{C}$. The preparation of tissues for measurement is outlined below and is based on previously published methods [7]. In brief, the left kidney was finely minced and was processed to isolate glomeruli and tubules. Glomeruli and tubules were separated by differential sieving with stainless steel mesh with pore sizes of 250-75 $\mu \mathrm{m}$ yielding 15-20,000 glomeruli/kidney. The aorta was homogenized by a Polytron homogenizer (U1tra-Tumax, Janke and Kunel, Staufen, Germany). The isolated renal glomeruli and tubules as well as the homogenized aorta were suspended in phosphate buffered saline $(\mathrm{pH} 7.4)$ followed by centrifugation of $15,000 \mathrm{rev} / \mathrm{min}$ for $30 \mathrm{~min}$ at $4{ }^{\circ} \mathrm{C}$. Lipid extraction of the pellet was performed by addition of $5 \mathrm{ml}$ of chloroform/methanol (2:1 vol/vol) followed by gentle shaking and standing overnight at $4^{\circ} \mathrm{C}$. The upper layer was removed and the pellet was washed three times each with methanol and distilled water. The pellet was then resuspended in $0.5 \mathrm{~mol} / \mathrm{l}$ acetic acid and $1 \mathrm{mg} / \mathrm{ml}$ pepsin, incubated for $18 \mathrm{~h}$ at $4^{\circ} \mathrm{C}$ to remove non-collagenous proteins, and washed twice with $0.1 \mathrm{~mol} / 1$ calcium chloride, $0.02 \mathrm{~mol} / 1$ Tris- $\mathrm{HCl}(\mathrm{pH} 7.5$ ) and $0.05 \%$ toluene. No specific fluorescence could be detected in the supernatants at this stage of the extraction procedure. The pellet was then digested with type IV collagenase $0.1 \mathrm{mg} / \mathrm{ml}$, (Sigma, St Louis, Mo., USA) and proteinase $\mathrm{K}$, $0.1 \mathrm{mg} / \mathrm{ml}$, (Sigma) by gentle shaking at $37^{\circ} \mathrm{C}$ for $72 \mathrm{~h}$ and centrifuged at $15,000 \mathrm{rev} / \mathrm{min}$ for $30 \mathrm{~min}$ at $4^{\circ} \mathrm{C}$. The resultant supernatant was used to measure collagen-related fluorescence with excitation/emission at $370 / 440 \mathrm{~nm}$. The fluorescence of an enzyme blank (type IV collagenase and proteinase K) was subtracted from the tissue fluorescence measurements. A colorimetric technique was used for the measurement of protein content [14] of the supernatants from each of the various tissue samples.

At 32 weeks, the renal cortex sorbitol content was measured by a specific radioisotopic assay [15]. Sorbitol was assayed in a two-step procedure which measured the amount of NADPH produced by sorbitol dehydrogenase.

Assessment of oxidative stress was carried out in plasma at 32 weeks by the measurement of thiobarbituric acid reactive substances (TBARS) [16]. In addition, TBARS were measured in renal homogenates from control and diabetic rats.

Serum lipid levels were measured at 32 weeks. Total cholesterol was assessed by an enzymatic colorimetric method 
Table 1. Body weight and glycaemic control of rats studied

\begin{tabular}{lclll}
\hline Group & $(n)$ & $\begin{array}{l}\text { Weight } \\
(\mathrm{g})\end{array}$ & $\begin{array}{l}\text { Glucose } \\
(\mathrm{mmol} / \mathrm{l})\end{array}$ & \multicolumn{1}{l}{$\begin{array}{l}\mathrm{HbA}_{1 \mathrm{c}} \\
(\%)\end{array}$} \\
\hline $\begin{array}{l}\text { Control } \\
\text { Diabetic }\end{array}$ & 12 & $715 \pm 27^{*}$ & $7.8 \pm 0.3^{*}$ & $2.1 \pm 0.1^{*}$ \\
$\begin{array}{l}\text { Diabetic }+ \\
\text { AG }\end{array}$ & 11 & $442 \pm 28$ & $31.7 \pm 4.8$ & $4.8 \pm 0.3$ \\
$\begin{array}{l}\text { Diabetic }+ \\
\text { BHT }\end{array}$ & 9 & $356 \pm 27$ & $36.3 \pm 0.5$ & $4.6 \pm 0.3$ \\
$\begin{array}{l}\text { Diabetic }+ \\
\text { prob }\end{array}$ & 12 & $422 \pm 36$ & $33.3 \pm 2.8$ & $4.7 \pm 0.3$ \\
$\begin{array}{l}\text { Diabetic }+ \\
\text { pon }\end{array}$ & 10 & $377 \pm 44$ & $33.2 \pm 5.2$ & $4.8 \pm 0.5$ \\
\hline
\end{tabular}

Results are mean \pm SEM for data at 32 weeks, ${ }^{a} p<0.01$ vs all other groups. AG, aminoguanidine; BHT, butylated hydroxytoluene; prob, probucol; pon, ponalrestat

(Monotest, cholesterol and triglycerides GP-PAP; Boehringer Mannheim, Mannheim, Germany). HDL-cholesterol was measured following precipitation with polyethylene gly$\operatorname{col} 6000$ [17].

\section{Statistical analysis}

Logarithmic transformation of urinary albumin data was performed to yield a normal distribution for this parameter. Comparison of normally distributed variables between the different groups during the study was performed by analysis of variance with or without repeated measures using the Statview SE Program (Brainpower, Calabasas, Calif., USA) on a Macintosh IIsi personal computer (Apple, Cupertino, Calif., USA). Comparisons between groups were performed by Fisher's least significant difference method. A $p$ value of less than 0.05 was viewed as statistically significant. All data are shown as mean \pm SEM unless otherwise specified.

\section{Results}

Body weight and glycaemic control at week 32 are shown in Table 1. After 16 weeks diabetic animals had lower body weight than control animals [control, $644 \pm 19$; diabetic, $342 \pm 36$; diabetic + aminoguanidine, $385 \pm 26$; diabetic + BHT, $247 \pm 27$; diabetic + probucol, $321 \pm 30 ;$ diabetic + ponalrestat, $282 \pm 43 \mathrm{~g}, p<0.01$ control vs other groups]. At 32 weeks diabetic rats had significantly lower body weight, higher plasma glucose and higher $\mathrm{HbA}_{1 \mathrm{c}} \mathrm{le}$ vels when compared to control rats (Table 1 ). Treatment with aminoguanidine, probucol, BHT or ponalrestat did not influence any markers of glycaemic control or body weight in diabetic animals. Mean plasma glucose levels over the study period performed every 8 weeks were increased to a similar degree in all the diabetic groups [control, $7.4 \pm 0.3$; diabetic, $32.5 \pm 2.4$; diabetic + aminoguanidine, $32.5 \pm$ 1.6; diabetic + BHT, $36.9 \pm 1.0$; diabetic + probucol, $36.4 \pm 1.3$; diabetic + ponalrestat, $34.2 \pm 3.0 \mathrm{mmol} / 1$,
A

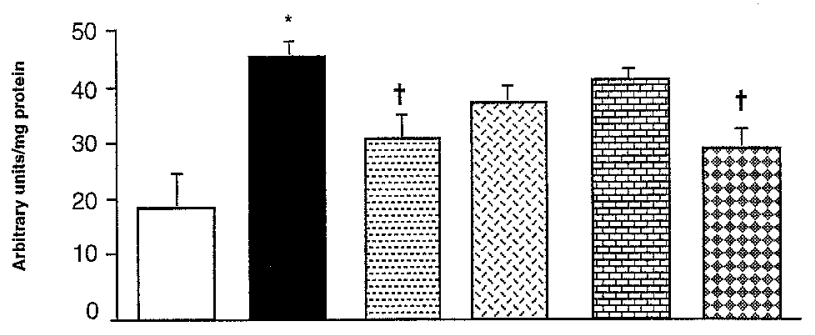

B



C

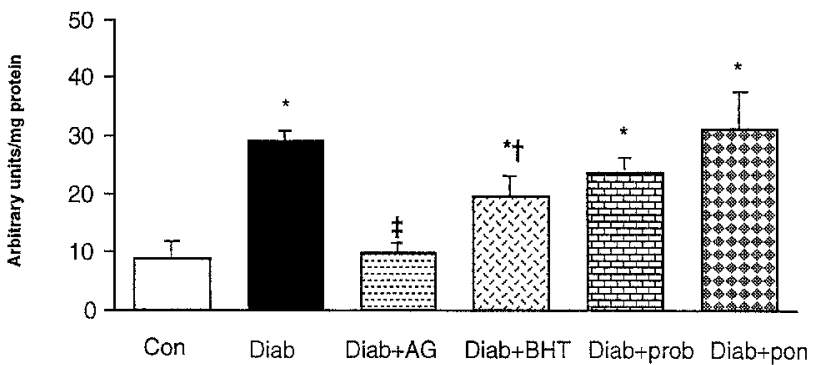

Fig. 1. (A-C) Fluorescence corrected for protein (arbitrary units/mg protein) in aorta (A), renal glomeruli (B), and renal tubules (C). Results are shown as mean \pm SEM at 32 weeks in control (Con), diabetic (Diab), diabetic + aminoguanidine $(\mathrm{Diab}+\mathrm{AG})$, diabetic + butylated hydroxytoluene (Diab + BHT), diabetic + probucol (Diab + prob), and diabetic + ponalrestat (Diab + pon) rats. $* p<0.01$ vs control; $\uparrow p<0.05 ;+p<0.01$ vs diabetic

$p<0.01$ control vs other groups]. A similar elevation in mean $\mathrm{HbA}_{1 \mathrm{c}}$ performed every 8 weeks was also observed in all the diabetic groups irrespective of treatment [control, $2.1 \pm 0.02$; diabetic, $4.5 \pm 0.2$; diabetic + aminoguanidine, $\quad 4.2 \pm 0.2 ; \quad$ diabetic + BHT, $4.6 \pm 0.2 ; \quad$ diabetic + probucol, $4.8 \pm 0.2$; diabetic + ponalrestat, $5.0 \pm 0.4 \%, p<0.01$ control vs other groups].

Tissue fluorescence data corrected for protein content in the aorta and kidney are shown in Figure 1. There was a significant increase in aortic fluorescence in diabetic rats. Aminoguanidine as well as ponalrestat therapy retarded the increase in aortic fluorescence in diabetic animals. Treatment of diabetic rats with probucol or BHT did not influence aortic fluorescence. In isolated renal tubules and glomeruli, fluorescence was significantly increased in diabetic animals. Treatment of diabetic rats with aminoguanidine totally prevented the increase in fluorescence observed in diabetic renal tubules and glomer- 

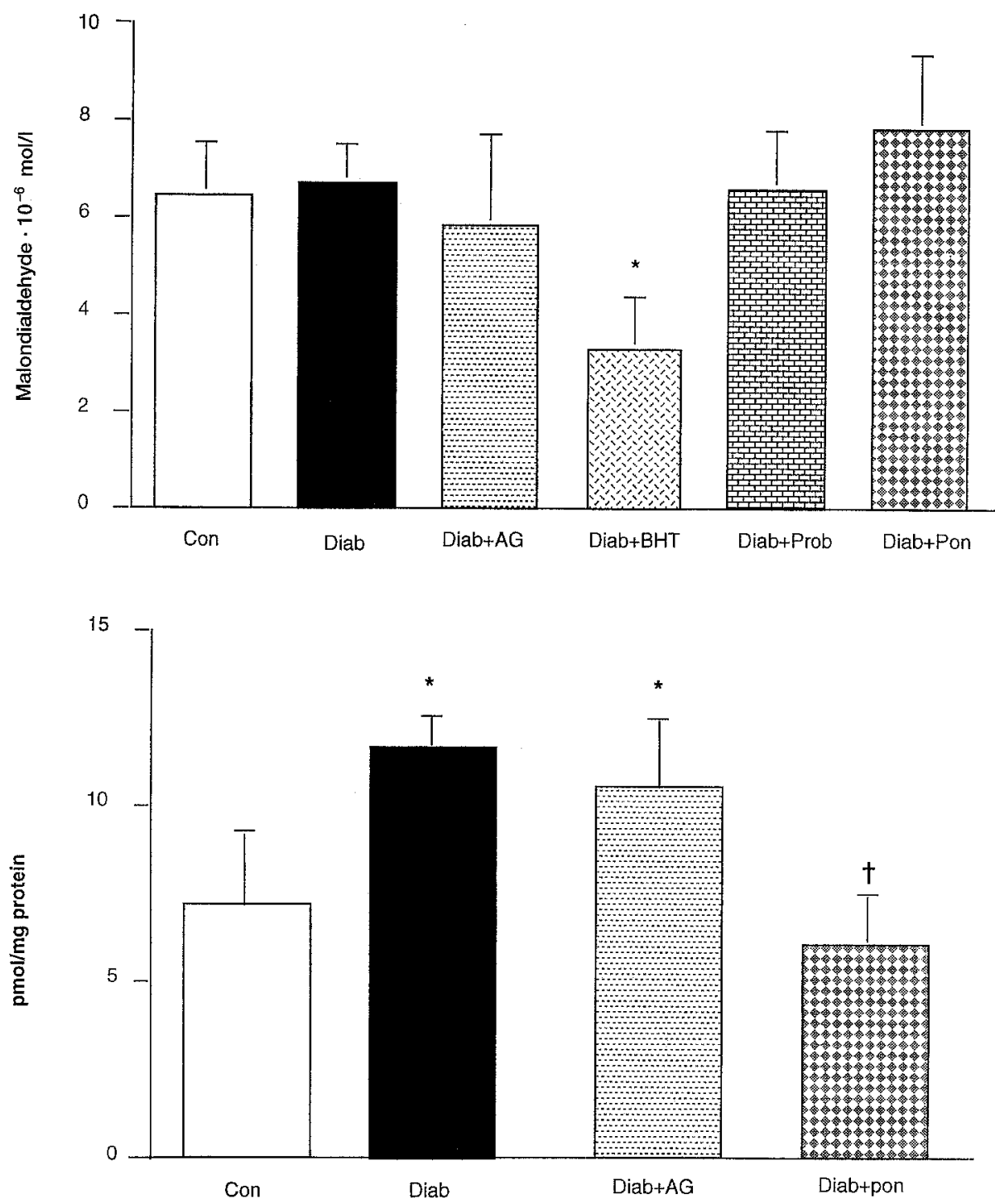

Fig. 2. Malondialdehyde content in plasma samples is shown for the various groups abbreviated as described in the legend to Figure 1. Results are shown as mean \pm SEM at 32 weeks. $* p<0.01$ vs diabetic
Fig.3. Renal cortex sorbitol levels in control (Con), diabetic (Diab), diabetic + aminoguanidine $(\mathrm{Diab}+\mathrm{AG})$ and diabetic + ponalrestat (Diab + pon) rats. Results are shown as mean \pm SEM at 32 weeks. * $p<0.01$ vs control; $\uparrow p<0.05$ vs diabetic uli. BHT reduced, but did not normalise, renal fluorescence levels. In contrast to the effects in the aorta, treatment of diabetic animals with ponalrestat did not affect fluorescence in renal tubules or glomeruli. Probucol did not reduce renal fluorescence.

Oxidative stress was assessed by measurement of plasma TBARS as shown in Figure 2. Diabetes itself did not affect plasma TBARS, nor did treatment with aminoguanidine, probucol or ponalrestat. The only reduction in plasma TBARS was observed in diabetic rats receiving BHT. The levels of renal TBARS were similar in control and diabetic rats (control $2.8 \pm 0.6$ vs diabetic $2.9 \pm 1.2$ nmol malondialdehyde/mg protein).

Renal aldose reductase activity as assessed by renal cortex sorbitol levels, at 32 weeks, is shown in Figure 3. Renal sorbitol levels were significantly increased in diabetic rats. Treatment of diabetic animals with ponalrestat normalised renal sorbitol levels. Aminoguanidine therapy did not influence renal cortex sorbitol levels in the diabetic rats.
Diabetic rats had elevated total cholesterol (control, $1.53 \pm 0.15 ;$ diabetic $2.83 \pm 0.25 \mathrm{mmol} / 1, p<$ 0.05 ) and HDL-cholesterol (control, $0.87 \pm 0.19$; diabetic $2.16 \pm 0.16 \mathrm{mmol} / \mathrm{l}, p<0.05$ ). Treatment of diabetic rats with probucol significantly reduced total cholesterol diabetic + probucol $2.37 \pm 0.14 \mathrm{mmol} / 1$, $p<0.05$ vs diabetic) and the reduction in HDL-cholesterol approached statistical significance (diabetic + probucol $1.85 \pm 0.12 \mathrm{mmol} / \mathrm{l}, p=0.055$ vs diabetic).

Urinary albumin data are shown in Figure 4. Diabetic animals had a progressive increase in urinary albumin excretion over the study period with levels elevated compared to control rats from week 8 onwards. Aminoguanidine (AG) retarded the rate of rise in albuminuria in diabetic rats $(F=8.39, p=0.014$, Diab vs Diab + AG; week 32 albuminuria; Diab, 30.9 vs. $\mathrm{Diab}+\mathrm{AG}, 5.6 \mathrm{mg} / 24 \mathrm{~h}$; geometric means shown) with urinary albumin excretion approaching but not reaching the levels observed in the control rats $(F=4.9, p=0.06$, Con vs Diab $+\mathrm{AG}$, week 32 albu- 
A

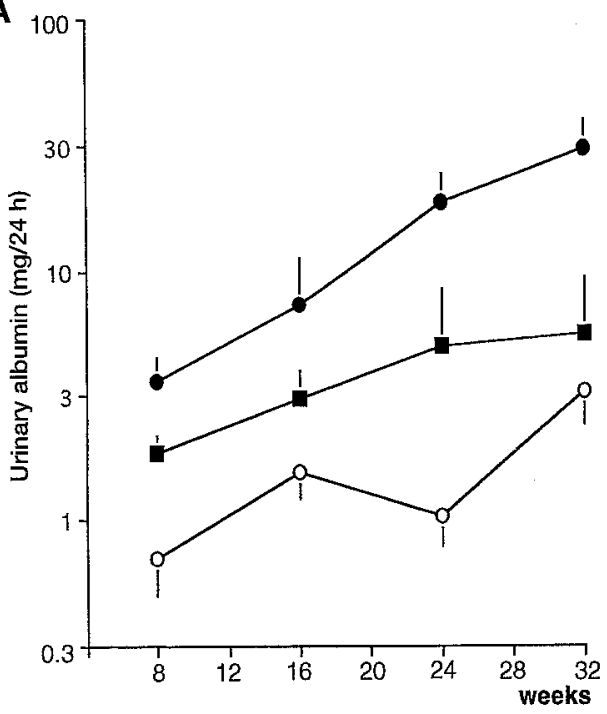

B



Fig. 4. (A, B) Serial data for albuminuria (y-axis, logarithmic scale) at 8 week intervals over 32 weeks are shown in the left panel (A) for control $(0)$, diabetic $(\bullet)$ and diabetic + aminoguanidine ( $\mathbf{a}$ ) rats. In the right panel $(\mathbf{B})$, data are shown for diabetic + probucol $(\diamond)$, diabetic + ponalrestat $(\square)$ and diabetic + butylated hydroxytoluene $(\triangle)$ groups. Results are shown as geometric means and tolerance factors. Statistical differences among groups are as below: Con vs Diab, Diab + BHT, Diab + pon, Diab + prob, $p<0.01$; Con vs Diab $+\mathrm{AG}, p=0.06$; Diab vs $\mathrm{Diab}+\mathrm{AG}, p=0.014 ;$ Diab vs Diab + BHT, $p=0.09$; Diab vs

Diab + pon, Diab + prob, NS;

Diab + AG vs Diab + pon, $p=0.02$;

Diab + AG vs Diab + prob, $p<0.01$;

Diab + AG vs Diab + BHT, $p=0.09$.

(ANOVA with repeated measures) minuria, Con $3.3 \mathrm{mg} / 24 \mathrm{~h}$ ). Probucol and ponalrestat did not reduce urinary albumin excretion when compared to untreated diabetic rats (week 32 urinary albumin excretion, Diab + prob, 24.5; Diab + pon, $21.4 \mathrm{mg} / 24 \mathrm{~h}$ ). Furthermore, aminoguanidine-treated rats had less albuminuria over the 32 -week study period than either probucol- $(F=12.5, p<0.001)$ or ponalrestat- $(F=7.6, p=0.02)$ treated rats. The effects of BTH on albuminuria in diabetic rats were intermediate between untreated and aminoguanidine-treated rats (week 32; $12.9 \mathrm{mg} / 24 \mathrm{~h}$, Diab + BHT vs Diab; $F=2.7, \quad p=0.09 ; \quad$ Diab + BHT vs Diab + AG, $F=2.69, p=0.09$ ).

\section{Discussion}

The present study has confirmed that the diabetes-related increase in tissue fluorescence is prevented by an inhibitor of advanced glycation. Inhibition of oxidation and aldose reductase produced only minor effects on tissue fluorescence and on albuminuria, suggesting that these processes are not the major components in the pathogenesis of diabetic nephropathy.

An acceleration of the Maillard reaction as reflected by increased collagen-related fluorescence has been well-documented both in experimental $[18,19]$ and human diabetes [20,21]. It has been suggested that the products of this reaction, AGEs, are involved in the pathogenesis of experimental diabetic nephropathy. Our previous study has shown a significant increase in collagen-related fluorescence over a 32week period of streptozotocin diabetes. Aminoguanidine, an inhibitor of advanced glycation [7] prevented increases in fluorescence in aorta as well as in renal tubules and glomeruli. In addition, aminoguanidine was able to prevent structural as well as functional aspects of diabetic nephropathy in the same rats by preventing mesangial expansion and retarding the development of albuminuria, respective1y. Since our initial studies a similar effect on albuminuria with aminoguanidine therapy has been observed in diabetic SHR [22] and diabetic Wistar rats [23]. It has also been shown that aminoguanidine therapy prevents increases in AGE products as assayed by a specific ELISA AGE assay [24]. Furthermore, aminoguanidine therapy has been observed to inhibit increases in haemoglobin-AGE in diabetic patients using a specific ELISA, consistent with its presumed action as an inhibitor of advanced glycation [25].

In the current study, aminoguanidine therapy did not have any effect on body weight, plasma glucose or $\mathrm{HbA}_{1 \mathrm{c}}$ in diabetic rats. After 32 weeks, rats receiving aminoguanidine had fluorescence levels similar to control rats in the aorta as well as in renal glomeruli and tubules. Throughout the 32-week study period, aminoguanidine was able to retard the diabetes-associated increase in urinary albumin excretion. However, aminoguanidine therapy did not affect renal cortex sorbitol levels in these rats, suggesting that aminoguanidine does not act as a potent aldose reductase inhibitor. These findings are confirmed by a recent study in which sorbitol levels in peripheral nerves were not affected by aminoguanidine treatment after 2 months of streptozotocin diabetes although there was an increase in nerve conduction velocity and a decrease in AGE levels in the same rats [26]. In contrast, previous studies have shown aminoguanidine to have aldose reductase inhibitory properties [27, 28] but the effects are weak and seen at concentrations much higher than would be observed in this study. Aminoguanidine was also not able to decrease oxidative stress as assessed by plasma TBARS after 32 weeks in diabetic rats. This suggests that aminoguanidine is not acting primarily as an antioxidant and confirms previous findings in diabetic rats [29]. In the latter 
study, 16 weeks of aminoguanidine therapy did not affect oxygen free-radical indices as measured by conjugated dienes and hydroperoxides.

In contrast to aminoguanidine, ponalrestat was a potent aldose reductase inhibitor as evidenced by normalisation of renal cortex sorbitol levels in diabetic rats. After 3 weeks of treatment, ponalrestat has been shown to attenuate urinary albumin excretion in diabetic rats [30]. In another study, ponalrestattreated diabetic Bio-Breeding (BB) rats had decreased proteinuria after 16 weeks of treatment but after 24 weeks, proteinuria was indistinguishable from levels in untreated diabetic rats [31]. In another study by Daniels and Hostetter [11], ponalrestat failed to show any effect on albuminuria in diabetic rats. In the present study, urinary albumin excretion was not ameliorated with ponalrestat, despite effective aldose reductase inhibition in the kidney. Interestingly, ponalrestat was able to prevent increases in collagen-related fluorescence in the aorta but not in glomeruli or renal tubules of diabetic rats. Previous long-term studies have also suggested a tissue-specific effect of aldose reductase inhibition on tissue fluorescence. For instance, aldose reductase inhibitors have been shown to retard development of fluorescence in the skin $[2,3]$ but not in the kidney [32] in diabetic rats. The inability of aldose reductase inhibition to attenuate fluorescence in the kidney while preventing increases in fluorescence in the aorta and skin may relate to differences in the predominant collagen in the various tissues. Kidney basement membranes contain type IV collagen whereas aorta and skin contain type I collagen $[33,34]$.

Collagen-linked fluorescence and pentosidine (an advanced glycation end product) have been shown to be essentially unresponsive to aldose reductase inhibition by sorbinil in the skin from galactosaemic rats whereas fluorescence was somewhat inhibited in the aortic tissue of the same rats [35]. The inhibition of aortic fluorescence in the galactosaemic rat is similar to the findings observed in the present study. However, the lack of an effect of aldose reductase inhibition on skin fluorescence in galactosaemic rats may be due to differences in the experimental models. Aldose reductase activity is significantly increased in the kidney of diabetic rats and ponalrestat reduces aldose reductase activity in the kidney as observed in the present study and by Ghahary et al. [36]. The lack of an effect on fluorescence in the kidney by ponalrestat despite effective aldose reductase inhibition may suggest that kidney fluorescence is unlikely to be related to the polyol pathway through fructosylation. Since there are well-documented beneficial effects of aldose reductase inhibition on the lens [37] and on experimental neuropathy [38], the present study provides further evidence that not all diabetic complications can be explained by a single pathogenic mechanism.
Recently, it has been suggested that diabetic complications may be partly attributed to oxidative stress $[5,39,40]$ although clear-cut evidence of oxidative stress in relation to diabetes remains to be shown. It has been proposed that increased glycation may predispose proteins to oxidative damage [41]. The exact sequence of events in this interaction between glycation and oxidation remains to be ascertained, with the classical view being that the oxidative changes occur subsequent to the initial glycation of proteins [41]. In contrast, it has been suggested that oxidative mechanisms are already operative before formation of the amadori products [42]. Recently, Hunt and Wolff [43] have proposed that glucose forms an enediol radical anion under physiological conditions which is further oxidised to a ketoaldehyde. This "autoxidation" of glucose yields the free radicals hydrogen peroxide and hydroxy radicals. This reaction may be accelerated in diabetes and the above compounds may then mediate the reaction of glucose with membrane proteins. Products of such 'glucoxidation' reactions also participate in the process of advanced glycation and result in the formation of carboxymethyl lysine which does not fluoresce [44, $45]$ and pentosidine $[46,47]$ which does fluoresce. Other in vitro studies have confirmed a link between glycation and oxidation since the addition of glucose or glycated collagen catalysed the peroxidation of polyunsaturated lipid vesicles [48]. Therefore, the processes of advanced glycation and lipid peroxidation may interact with each other, each process yielding fluorescent products. In our study, the antioxidants butylated hydroxytoluene (BHT) $[9,10]$ and probucol, a lipid-lowering agent with anti-oxidant properties $[49,50]$ were evaluated for their effects on tissue fluorescence and oxidative stress in relation to the development of diabetic complications.

Treatment of diabetic animals with probucol did not influence body weight, glucose or $\mathrm{HbA}_{1 \mathrm{c}}$ levels. Probucol therapy did not affect fluorescence in either aorta or the kidney nor did it influence oxidative stress as measured by plasma TBARS. However, there was evidence of a biochemical effect of this drug since at 32 weeks probucol significantly reduced cholesterol and HDL-cholesterol levels. Previous studies have confirmed the lipid-lowering effects of probucol $[8,51]$ and its ability to reduce HDL-cholesterol in rodents [51].

In diabetic rats, there was no increase in plasma or renal TBARS. The specificity of this assay as a marker of oxidative stress remains controversial. Recently, a lack of an increase in renal TBARS has been observed by two other groups evaluating this parameter in diabetic rats $[52,53]$. In the study by Parinandi et al. [52], TBARS were also measured in diabetic hearts and were actually reduced by about $50 \%$. Anti-oxidant treatment with BHT reduced oxidative stress, as shown by decreased plasma TBARS. Fur- 
thermore, there was a modest decrease in fluorescence and a possible anti-albuminuric effect. However, aminoguanidine was more effective in preventing increases in both parameters in experimental diabetes. This suggests that products of advanced glycation are the predominant source of fluorescence in the aorta and kidney. However, the partial effects of BHT on tissue fluorescence may indicate that oxidation accelerates the Maillard process. Nevertheless, without detailed characterisation of the nature of the fluorescent products in diabetic tissues, the contribution of oxidative products to the genesis of diabetesassociated fluorophores and albuminuria cannot be ascertained. The lack of an effect of probucol on plasma TBARS may indicate that BHT is a more effective anti-oxidant than probucol in this experimental model or that the dose of probucol was not optimized. Probucol therapy seemed to lower urinary albumin excretion for the first 16 weeks of treatment, but after this albuminuria approached levels similar to untreated diabetic rats. One possibility is that probucol had additional actions such as an anti-diabetic action [54]. This was not the case in the present study, since there was no evidence of lower blood glucose levels in the probucol-treated group. The failure of any of the other drugs to reproduce the effects of aminoguanidine, despite these agents acting as inhibitors of oxidative stress or aldose reductase, suggests that aminoguanidine is acting predominantly although probably not exclusively, by inhibition of advanced glycation. However, the recent in vitro data suggesting that aminoguanidine may be a nitric oxide inhibitor [55] indicate that other actions of aminoguanidine need to be investigated. It should be stressed that the present study has examined the in vivo effects of advanced glycation by indirect methods, using antioxidants and aldose reductase inhibitors as probes. Definitive analysis of the mechanisms involved in the in vivo action of advanced glycation awaits direct measurement of advanced glycation product levels.

Acknowledgements. This study was supported by grants from the Juvenile Diabetes Foundation International and the Central Health and Medical Research Council.

\section{References}

1. Bucala R, Makita Z, Koschinsky T, Cerami A, Vlassara H (1993) Lipid advanced glycosylation: pathway for lipid oxidation in vivo. Proc Natl Acad Sci USA 90: 6434-6438

2. Odetti PR, Borgoglio A, De Pascale A, Rolandi R, Adezati $L$ (1990) Prevention of diabetes-increased aging effect on rat collagen-linked fluorescence by aminoguanidine and rutin. Diabetes 39: 796-801

3. Suarez G, Rajaram R, Kailash CB, Ororisky AL, Goidl JA (1988) Administration of an aldose reductase inhibitor induces a decrease of collagen fluorescence in diabetic rats. J Clin Invest 82: 624-627
4. Ahmed N, Furth AJ (1992) Failure of common glycation assays to detect glycation by fructose. Clin Chem $38(7)$ : 1301-1303

5. Baynes JW (1991) Role of oxidative stress in development of complications in diabetes. Diabetes 40: 405-412

6. Chisolm GM, Irwin KC, Penn MS (1992) Lipoprotein oxidation and lipoprotein-induced cell injury in diabetes. Diabetes 41 [Suppl 2]: 61-66

7. Soulis-Liparota T, Cooper M, Papazoglou D, Clarke B, Jerums G (1991) Retardation by aminoguanidine of development of albuminuria, mesangial expansion, and tissue fluorescence in streptozocin-induced diabetic rat. Diabetes $40: 1328-1334$

8. Tada H, Oida K, Kutsumi Y, Shimada Y, Nakai T, Miyabo $S$ (1992) Effects of probucol on impaired cardiac performance and lipid metabolism in streptozocininduced diabetic rats. J Cardiovasc Pharmacol 20: 179186

9. Srivastava SK, Ansari NH (1988) Prevention of sugar-induced caractogenesis in rats by butylated hydroxytoluene. Diabetes 37: 1505-1508

10. Cameron NE, Cotter MA, Maxfield EK (1993) Anti-oxidant treatment prevents the development of peripheral nerve dysfunction in streptozotocin-diabetic rats. Diabetologia 36: 299-304

11. Daniels BS, Hostetter TH (1989) Aldose reductase inhibition and glomerular abnormalities in diabetic rats. Diabetes 38: 981-986

12. Schmidht FH (1961) Enzymatic determination of glucose and fructose simultaneously. Klin Wochenschr 39: 12441247

13. Cooper ME, Allen TJ, Macmillan P et al. (1991) Effect of genetic hypertension on diabetic nephropathy in the ratfunctional and structural characteristics. J Hypertens 6 : 1009-1016

14. Bradford MM (1976) A rapid and sensitive method for the quantification of microgram quantities of protein utilizing the principle of protein-dye binding. Anal Biochem 72: $248-254$

15. Sener A, Malaisse WJ (1990) A sensitive radioisotopic method for the measurement of NAD(P)H: its application to the assay of metabolites and enzymatic activities. Anal Biochem 186: 236-242

16. Wills ED (1969) Lipid peroxide formation in microsomes. Biochem J 113: 315-324

17. Cooper ME, Vranes DA, Panagiotopoulos S, Allen GJ, Goodall I, Jerums G (1990) Hyperlipidaemia increases albuminuria in hypertensive and normotensive rats. Clin Exp Pharmacol Physiol 17: 225-228

18. Soulis T, Cooper ME, Layton G, Allen T, Jerums G (1988) Aminoguanidine reduces tissue fluorescence but not albuminuria in diabetic rats: In: Ryal RG (ed) Proceedings. Glycated proteins in diabetes mellitus. Univ of Adelaide, Adelaide, Australia, p 310-320

19. Brownlee M, Vlassara H, Kooney A, Ulrich P, Cerami A (1986) Aminoguanidine prevents diabetes-induced arterial protein cross-linking. Science 232: 1629-1632

20. Monnier VM, Kohn RR, Cerami A (1984) Accelerated age-related browning of human collagen in diabetes mellitus. Proc Natl Acad Sci 81: 583-587

21. Beisswenger PJ, Moore LL, Curphey TJ (1993) Relationship between glycemic control and collagen-linked advanced glycation and products in type I diabetes. Diabetes Care 16(5): 689-694

22. Edelstein D, Brownlee M (1992) Aminoguanidine ameliorates albuminuria in diabetic hypertensive rats. Diabetologia 35(1): 96-97 
23. Itakura M, Yoshikawa H, Bannai C et al. (1991) Aminoguanidine decreases urinary albumin and high-molecular weight proteins in diabetic rats. Life Sci 49: 889-897

24. Vlassara H, Fuh H, Makita Z, Krungkrai S, Cerami A, Bucala R (1992) Exogenous advanced glycosylation end products induce complex vascular dysfunction in normal animals: a model for diabetic and aging complications. Proc Natl Acad Sci USA 89: 12043-12047

25. Makita Z, Vlassara H, Rayfield et al. (1992) HemoglobinAGE: a circulating marker of advanced glycosylation. Science 258(5082): 651-653

26. Cameron NE, Cotter MA, Dines K, Love A (1992) Effects of aminoguanidine on peripheral nerve function and polyol pathway metabolites in streptozotocin-diabetic rats. Diabetologia 35: 946-950

27. Kumari K, Umar S, Bansal V, Sahib MK (1991) Monoaminoguanidine inhibits aldose reductase. Biochem Pharmacol 4: 1527-1528

28. Kumari K, Umar S, Bansal B, Sahib MK (1991) Inhibition of diabetes-associated complications by nucleophilic compounds. Diabetes 40: 1079-1084

29. Kihara M, Schmelzer JD, Poduslo JF, Curran GL, Nicklander KK, Low PA (1991) Aminoguanidine effects on nerve blood flow, vascular permeability, electrophysiology, and oxygen free radicals. Proc Natl Acad Sci USA 88: 6107-6111

30. Chang WP, Dimitriadis E, Allen T, Dunlop ME, Cooper M, Larkins RG (1991) The effect of aldose reductase inhibitors on glomerular prostaglandin production and urinary albumin excretion in experimental diabetes mellitus. Diabetologia 34: 225-231

31. Beyer-Mears A, Murray FT, Cruz E, Rountree J, Sciadini M (1992) Comparison of sorbinil and ponalrestat (Statil) diminution of proteinuria in the BB rat. Pharm 45: 285-291

32. Cohen MP, Klepser H, Wu VL (1991) Evaluation of the effect of aldose reductase inhibition on increased basement collagen fluorescence in diabetic rats. Gen Pharmacol 22: 603-606

33. Maurel E, Shuttleworth CA, Bouissou H (1987) Interstitial collagens and ageing in human aorta. Virchows Arch A (Pathol Anat Histopathol) 410: 383-390

34. Martinez-Hernandez A, Amenta PS (1983) The basement membrane in pathology. Lab Invest 48: 656-677

35. Richard S, Tamas C, Sell DR, Monnier VM (1991) Tissuespecific effects of aldose reductase inhibition on fluorescence and cross-linking of extracellular matrix in chronic galactosemia. Diabetes 40: 1049-1056

36. Ghahary A, Chakrabarti S, Sima AAF, Murphy LJ (1991) Effect of insulin and statil on aldose reductase expression in diabetic rats. Diabetes 40: 1391-1396

37. Reddy VN, Lin LR, Giblin FJ, Lou M, Kador PF, Kinoshita JH (1992) The efficacy of aldose reductase inhibitors on polyol accumulation in human lens and retinal pigment epithelium in tissue culture. J Ocul Pharmacol 8: 43-52

38. Carmeron NE, Leonard MB, Ross IS, Whiting PH (1986) The effects of sorbinil on peripheral nerve conduction velocity, polyol concentrations and morphology in the streptozotocin-diabetic rat. Diabetologia 29: 168-174

39. Lyons TJ (1993) Glycation and oxidation: a role in the pathogenesis of atherosclerosis. Am J Cardiol 71: 26 B-31 B
40. Kristal BS, Yu BP (1992) An emerging hypothesis: synergistic induction of aging by free radicals and Maillard reactions. J Gerontol 47(4): B 107-B 114

41. Hodge JE (1953) Dehydrated foods: chemistry of browning reactions in model systems. Agric Food Chem 1: 928-943

42. Hayashi T, Namiki M (1986) Role of sugar fragmentation in the Maillard reactions. In: Fujimaki M, Namiki M, Kato $\mathrm{H}$ (eds) Amino-carbonyl reactions in food and biological systems. Elsevier, Amsterdam, pp 29-38

43. Hunt JV, Wolff SP (1991) Oxidative glycation and free radical production: a causal mechanism of diabetic complications. Free Rad Res Comms 12-13: 115-123

44. McCance DR, Dyer DG, Dunn JA et al. (1993) Maillard reaction products and their relation to complications in insulin-dependent diabetes mellitus. J Clin Invest 91: 2470 2478

45. Fu MX, Wells-Knecht KJ, Blackledge JA, Lyons TJ, Thorpe SR, Baynes JW (1994) Glycation, glyoxidation and crosslinking of collagen by glucose. Diabetes 43: 676-683

46. Sell DR, Lapolla A, Odetti P, Fogarty J, Monnier VM (1992) Pentosidine formation in skin correlates with severity of complications in individuals with long-standing IDDM. Diabetes 41: 1286-1292

47. Odetti P, Fogarty J, Sell DR, Monnier VM (1992) Chromatographic quantitation of plasma and erythrocyte pentosidine in diabetic and uremic subjects. Diabetes 42: 153 159

48. Hicks M, Delbridge L, Yue DK, Reeve TS (1988) Catalysis of lipid peroxidation by glucose and glycosylated collagen. Biochem Biophys Res Commun 151: 649-655

49. Parthasarathy S, Young SG, Witztum JL, Pittman RC, Steinberg D (1986) Probucol inhibits oxidative modification of low density lipoprotein. J Clin Invest 77: 641-644

50. Carew TE, Schwenke DC, Steinberg D (1987) Antiatherogenic effect of probucol unrelated to its hypocholesterolemic effect: evidence that antioxidants in vivo can selectively inhibit low density lipoprotein degradation in macrophage-rich fatty streaks and slow the progression of athersclerosis in the watanabe heritable hyperlipidemic rabbit. Proc Natl Acad USA Sci 84: 7725-7729

51. Mamo JC, Elsegood CL, Umeda Y, Hirano T, Redgrave TG (1993) Effect of probucol on plasma clearance and uptake of chylomicrons and VLDLs in normal and diabetic rats. Arterioscler Thromb 13: 231-239

52. Parinandi NI, Thompson EW, Schmid HH (1990) Diabetic heart and kidney exhibit increased resistance to lipid peroxidation. Biochim Biophys Acta 1047: 63-69

53. Oster MH, Llobet JM, Domingo JL, German JB, Keen CL (1993) Vanadium treatment of diabetic sprague dawley rats results in tissue vanadium accumulation and pro-oxidant effects. Toxicology 83: 115-130

54. Yoshino G, Matsushita M, Maeda et al. (1992) Effect of probucol on recovery from streptozotocin diabetes in rats. Horm Metab Res 24: 306-309

55. Tilton RG, Chang K, Hasan KS et al. (1993) Prevention of diabetic vascular dysfunction by guanidines. Inhibition of nitric oxide synthase versus advanced glycation end-product formation. Diabetes 42: 221-232 